\title{
Determinants of postpartum anemia among women from a rural population in southern India
}

This article was published in the following Dove Press journal:

International Journal of Women's Health

II April 2014

Number of times this article has been viewed

\section{PS Rakesh'}

Vijayaprasad Gopichandran²

Dimple Jamkhandi'

Krishna Manjunath'

Kuryan George'

Jasmin Prasad'

'Department of Community Health, Christian Medical College, Vellore,

${ }^{2}$ School of Public Health, SRM

University, Kanchipuram District,

Tamil Nadu, India
Correspondence: PS Rakesh

Department of Community Health, Christian Medical College,

Vellore 632004, Tamil Nadu, India

Tel +9l 9495537333

Email rakeshrenjini@gmail.com
Background: Even though the problem of anemia during pregnancy has been adequately emphasized, very little attention has been paid to postpartum anemia. The objective of the current study was to estimate the mean change in maternal hemoglobin from 36 weeks' gestation to 6 weeks postpartum and to identify the factors associated with anemia during the postpartum period among women in a rural development block in Tamil Nadu, India.

Methods: Ninety-three pregnant women were interviewed using a structured questionnaire at 36 weeks' gestation and then at 2 and 6 weeks postpartum. Blood samples were collected from the participants at 36 weeks' gestation and at 6 weeks postpartum. Paired $t$-tests assessing the difference in mean hemoglobin prepartum and postpartum, univariate analysis, and multiple logistic regression to identify factors associated with postpartum anemia were done using Statistical Package for the Social Sciences version 12 for Microsoft Windows software.

Results: The proportion of study subjects who were anemic (hemoglobin $<11 \mathrm{~g} / \mathrm{dL}$ ) at 36 weeks' gestation was $26.8 \%$ and at 6 weeks postpartum was $47.3 \%$ (hemoglobin $<12 \mathrm{~g} / \mathrm{dL}$ ). The mean hemoglobin at 36-38 weeks' gestation was $11.70 \pm 1.43 \mathrm{~g} / \mathrm{dL}$ and at 6 weeks postpartum was $12.10 \pm 1.27 \mathrm{~g} / \mathrm{dL}$. Anemia at 36 weeks' gestation (odds ratio [OR] 10.47, 95\% confidence interval [CI] 2.37-42.34), heavy blood loss perceived by the mother during delivery (OR 12.91, 95\% CI 2.01-61.25), younger maternal age ( $<21$ years, OR $2.45,95 \%$ CI $1.28-23.86)$, and inadequate iron supplementation during the postpartum period (OR 3.53, 95\% CI 1.18-11.37) were identified as significant factors associated with anemia at 6 weeks postpartum.

Conclusion: Anemia during the third trimester of pregnancy, heavy bleeding perceived by the mother during delivery, younger maternal age, and inadequate iron supplementation during the postpartum period were associated with postpartum anemia.

Keywords: anemia, hemoglobin, iron deficiency, postpartum

\section{Introduction}

Anemia is one of the leading causes of disability and is a major global public health problem. ${ }^{1}$ Even though the problem of iron deficiency in pregnancy is adequately emphasized, very little attention has been paid to postpartum anemia.

Coverage of antenatal care has improved in India, especially after implementation of the National Rural Health Mission, which was launched in 2005 to provide accessible, affordable, and quality health care to rural populations, but care during the postpartum period remains poor. ${ }^{2}$ After delivery, maternal hemoglobin status is expected to improve as the expanded red cell mass of pregnancy contracts and a large proportion of iron returns to body stores. ${ }^{3}$ However, recent studies have reported that postpartum iron deficiency and anemia are more common than expected. ${ }^{4-9}$ The prevalence of 
postpartum anemia in developing countries ranges from $50 \%$ to $80 \% .{ }^{10}$ Postpartum anemia is common among low-income women, even in resource-rich countries. ${ }^{11,12}$ In a study of women of low socioeconomic status in the USA, 21\% with normal hemoglobin at the third trimester developed anemia postpartum. ${ }^{13}$ These estimates signal postpartum anemia as a public health problem that warrants greater attention.

Maternal anemia affects postpartum emotion and cognition, ${ }^{14}$ and a low hemoglobin level has been found to be associated with postpartum depression. ${ }^{15}$ Anemia during the postpartum period can be a contributing factor for low milk supply, delayed wound healing, low immunity, and increased susceptibility to mastitis, ductitis, and urinary tract infection. ${ }^{16,17}$ Therefore, postpartum anemia occurring when the mother is learning to parent and take care of her baby will have major consequences and warrants greater attention and higher quality care.

The objective of the current study was to estimate the mean change in hemoglobin from 36 weeks' gestation to 6 weeks postpartum and to identify factors associated with anemia during the postpartum period in women from a rural development block in Tamil Nadu, India. The findings from the study will aid health care providers and policy makers to propose targeted interventions to improve the health status of postnatal mothers.

\section{Materials and methods}

The community health department at the Christian Medical College in Vellore provides primary health care to a population of over 120,000 across 82 villages in a Tamil Nadu rural development block. Pregnant women are examined monthly at a mobile antenatal clinic. Women with strong antenatal risk factors are referred to a high-risk clinic held weekly at the base hospital where they are examined by a senior physician. Health care in the block is also provided by three primary health centers and a government medical college.

Data on reporting of marriages, eligible couples, pregnancies, deliveries, births, immunization, deaths, and morbidity in each village is collected by frontline workers known as health aides, who collect information during home visits, record the data in appropriate registers, and pass them on to the public health nurse. The information is then verified and maintained as an electronic database in the health information system within the department. This surveillance system has been described in detail elsewhere. ${ }^{18}$

All antenatal women at 36-38 weeks' gestation who were permanent residents of the block from March 1, 2011, to April 30, 2011 were eligible to participate in this study.
Women with previously diagnosed hematological abnormalities other than iron deficiency anemia and those who were planning to go to their mother's home located outside the district for delivery were excluded because of the likely difficulties in gathering postpartum information. The same women were visited in their homes within the first 2 weeks of delivery and again 6-8 weeks postpartum. To detect an effect size not lower than a change in hemoglobin of $0.5 \mathrm{~g} / \mathrm{dL}$ with a significance level of $95 \%, 90 \%$ power, and a standard deviation of 1.5 , the required sample size was calculated to be $77 .{ }^{13}$ Because many women go to their mothers' homes for delivery and would be difficult to follow up thereafter, an extra further $30 \%$ were planned to be enrolled in the study. A list of all pregnant women in the block who were at 36-38 weeks' gestation was obtained from the database of the health information system. The study was approved by the institutional review board and ethics committee at the Christian Medical College, Vellore.

After obtaining written informed consent, the pregnant women were interviewed using a structured questionnaire in their homes at 36-38 weeks' gestation. Details including sociodemographic information, obstetric history, antenatal care and complications, and details of consumption of iron and folic acid tablets during pregnancy were collected during the visit. One milliliter of blood was collected by venipuncture into an ethylenediamine tetraacetic acid-coated bottle for estimation of hemoglobin. The same women were visited again within 2 weeks of delivery, and information regarding details of delivery including place, mode, and outcome of delivery, perceived blood loss during and after delivery, and complications at the time of delivery was collected. The final visit was at 6-8 weeks after delivery during which details of iron intake, visits by health workers, and any morbidity during the postpartum period were collected. A second blood sample was collected during the last visit for estimation of hemoglobin. All samples were processed within 2 hours of collection at the base hospital laboratory. Hemoglobin was estimated using a KX21 analyzer (Sysmex America, Inc., Lincolnshire, IL, USA), which is an automated device using a noncyanide method for analysis of hemoglobin. A modified Kuppuswamy scale for household income, education, and occupation status was used to assess socioeconomic status. ${ }^{19}$

The data were entered using Epi Info 2001 version 3.2.2 software and the statistical analysis was done using Statistical Package for Social Sciences version 12 software for Windows (SPSS Inc., Chicago, IL, USA). Changes in women classified as having a rise in hemoglobin after delivery and those 
who had a fall in hemoglobin were assessed separately. The mean interval rise and fall in hemoglobin and the overall direction of change in hemoglobin were determined in the study population. Mean hemoglobin concentrations during the antepartum and postpartum periods were compared using the paired $t$-test. Maternal age was categorized with a cut-off of 21 years, given that the preferred age of marriage for women according to India's National Population Policy is 20 years. Anemia during pregnancy was defined as hemoglobin $<11 \mathrm{~g} / \mathrm{dL}$ (World Health Organization cut-off for defining anemia during pregnancy) and less than $12 \mathrm{~g} / \mathrm{dL}$ (World Health Organization cut-off for defining anemia in nonpregnant women) during the 6-8 weeks postpartum. ${ }^{20}$ Univariate analysis of factors associated with postpartum anemia was done, and chi-squared and prevalence odds ratios (ORs) were calculated. Multiple logistic regression was used to identify factors associated with postpartum anemia and adjusted ORs were calculated.

\section{Results}

One hundred and thirty-nine pregnant women were eligible for inclusion in the study. Twenty-three were not included because they planned to deliver in their mothers' homes, as is the tradition, and so were not available for follow-up. A total of 116 women were visited initially, of whom 21 were not available for interview at a second visit after delivery because they had changed their plans and went to their mothers' homes for delivery $(n=20)$ or moved out of the study area $(n=1)$. Another participant withdrew her consent and a further participant had a blood transfusion at term; both women were excluded from analysis. The mean age of the study participants was $22.9 \pm 3.46$ years. Their demographic details are shown in Table 1, and their relevant obstetric, antenatal, intrapartum, and postpartum details are shown in Table 2.

Mean hemoglobin at 36-38 weeks' gestation was $11.70 \pm 1.43 \mathrm{~g} / \mathrm{dL}$ and at 6 weeks postpartum was $12.10 \pm 1.27 \mathrm{~g} / \mathrm{dL}$. The mean rise in hemoglobin between 36 weeks' gestation and 6 weeks postpartum was $0.40 \mathrm{~g} / \mathrm{dL}(95 \%$ CI $0.21-0.60, P<0.001)$. Hemoglobin increased by $>1 \mathrm{~g} / \mathrm{dL}$ in $27.9 \%$ (26/93) of participants. The proportion of women who were anemic (hemoglobin $<11 \mathrm{~g} / \mathrm{dL}$ ) at 36 weeks' gestation was $26.8 \%(25 / 93)$. At 6 weeks postpartum, $47.3 \%$ (44/93) had hemoglobin $<12 \mathrm{~g} / \mathrm{dL}$ and $18.2 \%$ (17/93) had hemoglobin $<11 \mathrm{~g} / \mathrm{dL}$.

The hemoglobin level at 6 weeks postpartum had dropped from the third trimester value in 30\% (28/93) of the women. Seventy-six percent $(19 / 25)$ of women
Table I Sociodemographic characteristics of the study population $(n=93)$

\begin{tabular}{lll}
\hline Characteristics & Categories & $\mathbf{n}(\%)$ \\
\hline Age, years & $<2$ I & $24(25.8)$ \\
& $2 I-25$ & $5 I(54.8)$ \\
Educational status & $>25$ & $18(19.4)$ \\
& $<5$ th grade & $03(3.3)$ \\
& 5-8th grade & $17(18.3)$ \\
& 9-I0th grade & $39(41.9)$ \\
& II-I2th grade & $25(26.9)$ \\
Religion & Degree/postgraduate & $09(9.7)$ \\
& Hindu & $76(81.7)$ \\
Occupation & Christian & $12(12.9)$ \\
& Muslim & $05(5.3)$ \\
& Housewife & $85(91.4)$ \\
& Unskilled laborer & $03(3.3)$ \\
Socioeconomic status & Skilled laborer & $02(2.1)$ \\
& Professional/semiprofessional & $03(3.3)$ \\
& Upper & - \\
& Upper middle & $09(9.7)$ \\
& Lower middle & $26(28)$ \\
& Upper lower & $53(57)$ \\
& Lower & $05(5.4)$ \\
\hline
\end{tabular}

classified as having anemia (hemoglobin $<11 \mathrm{~g} / \mathrm{dL}$ ) at 36 weeks' gestation remained anemic at 6 weeks postpartum (hemoglobin $<12 \mathrm{~g} / \mathrm{dL}$ ); while $36.6 \%$ (25/68) of women who were not anemic (hemoglobin $\geq 11 \mathrm{~g} / \mathrm{dL}$ ) during the third trimester had hemoglobin $<12 \mathrm{~g} / \mathrm{dL}$ at 6 weeks postpartum.

The results for univariate analysis of factors associated with anemia during the 6-8 weeks postpartum are shown in Table 3. All variables found to be significantly associated with postpartum anemia in the univariate analysis were included in the multivariate analysis. The number of iron tablets consumed during pregnancy and postpartum morbidity were also included. Maternal age at delivery $(<21$ years), inadequate iron and folic acid supplementation ( $<100$ tablets) during pregnancy, total number of visits to the antenatal clinic $(<5)$, anemia at 36 weeks' gestation (hemoglobin $<11 \mathrm{~g} / \mathrm{dL}$ ), blood loss perceived by the mother during delivery (heavy/moderate), inadequate intake of iron and folic acid during the postpartum period $(<30)$, and any postpartum morbidity were entered into a logistic regression model. In this model, younger maternal age, ie, $<21$ years (OR 2.45, 95\% CI 1.28-23.86), anemia at 36 weeks' gestation (OR 10.47, 95\% CI 2.37-42.34), heavy blood loss perceived by mother during delivery (OR 12.91, 95\% CI 2.01-61.25), and inadequate iron supplementation during the postpartum period (OR 3.53, 95\% CI 1.18-11.37) were significantly associated with postpartum anemia at 6 weeks. The logistic regression model is shown in Table 4. 
Table 2 Obstetric, antenatal, intrapartum, and postpartum characteristics of the study population

\begin{tabular}{|c|c|c|}
\hline Characteristics & Categories & n (\%) \\
\hline \multirow[t]{3}{*}{ Order of pregnancy } & 1 & $42(45.2)$ \\
\hline & 2 & $34(36.6)$ \\
\hline & $\geq 3$ & $17(18.2)$ \\
\hline \multirow[t]{5}{*}{ Strong risk factors } & No high risk & $81(87.1)$ \\
\hline & Previous stillbirth/neonatal death & $07(7.5)$ \\
\hline & Previous cesarean section & $02(2.2)$ \\
\hline & Abnormal presentation & $01(1.1)$ \\
\hline & Previous preterm & $02(2.2)$ \\
\hline Visits to antenatal & $<3$ & Nil \\
\hline \multirow[t]{2}{*}{ clinic (n) } & $3-5$ & $10(10.8)$ \\
\hline & $>5$ & $83(89.2)$ \\
\hline IFA tablets & $<50$ & $08(8.9)$ \\
\hline consumed during & $5 I-100$ & $13(13.9)$ \\
\hline antenatal period $(n)$ & $\geq 100$ & $72(77.4)$ \\
\hline \multirow[t]{2}{*}{ Place of delivery } & Primary health center & $28(30.1)$ \\
\hline & Higher center & $65(69.8)$ \\
\hline Perceived blood loss & Do not know & $05(5.4)$ \\
\hline \multirow[t]{3}{*}{ at time of delivery } & Mild & $20(21.5)$ \\
\hline & Moderate & $29(3 \mid .2)$ \\
\hline & Heavy & $39(41.9)$ \\
\hline Consumption of IFA & Not taken at all & $36(39.1)$ \\
\hline tablets in postpartum & $0-14$ & $16(17.2)$ \\
\hline \multirow[t]{2}{*}{ period, days } & $15-29$ & $03(3.3)$ \\
\hline & $\geq 30$ & $38(40.7)$ \\
\hline Postnatal visits by & No visits at all & $05(5.4)$ \\
\hline \multirow[t]{3}{*}{ any health worker } & I & $54(58.1)$ \\
\hline & 2 & $33(35.5)$ \\
\hline & $>2$ & $0 \mathrm{I}(\mathrm{I} . \mathrm{I})$ \\
\hline
\end{tabular}

Abbreviation: IFA, iron and folic acid.

\section{Discussion}

The change in hemoglobin values during the postpartum period in a setting of optimal antenatal care would be of great use because it can provide a baseline against which comparisons can be made for the rest of the country. This study highlights postpartum anemia as a significant public health problem. It also identified several factors associated with postpartum anemia, including antepartum anemia and blood loss during delivery, which have policy implications. The mean rise in hemoglobin at 6 weeks postpartum from the value at 36 weeks' gestation was $0.4 \mathrm{~g} / \mathrm{dL}(0.21-0.60)$ in our study population. Currently, there are no separate cut-off values defined by the World Health Organization for the postpartum period. Previous researchers have used the cut-off for defining anemia in nonpregnant women (hemoglobin $<12 \mathrm{~g} / \mathrm{dL}$ ) as the cut-off for defining anemia in postpartum women. ${ }^{5,7}$ The cut-offs for defining anemia (hemoglobin $<12 \mathrm{~g} / \mathrm{dL}$ ) in nonpregnant women set by the World Health Organization demand an increase of $1 \mathrm{~g} / \mathrm{dL}$ for a mother who was classified as nonanemic during pregnancy (hemoglobin $\geq 11 \mathrm{~g} / \mathrm{dL}$ ) to continue to be in same status at 6 weeks postpartum. ${ }^{20}$

In the current study, the prevalence of anemia during the antepartum and postpartum periods are on the lower side when compared with reports from other parts of the country

Table 3 Univariate analysis of factors associated with anemia at 6 weeks postpartum $(n=93)$

\begin{tabular}{|c|c|c|c|c|c|}
\hline \multirow[t]{2}{*}{ Characteristics } & \multirow[t]{2}{*}{ Categories } & \multicolumn{2}{|c|}{ Anemia at 6 weeks postpartum } & \multirow{2}{*}{$\begin{array}{l}\text { Chi-square } \\
P \text {-value }\end{array}$} & \multirow{2}{*}{$\begin{array}{l}\text { Prevalence } \\
\text { OR }(95 \% \mathrm{Cl})\end{array}$} \\
\hline & & $\begin{array}{l}\text { Anemia } \\
(<12 \text { g\%) }\end{array}$ & $\begin{array}{l}\text { No anemia } \\
(>12 \mathrm{~g} \%)\end{array}$ & & \\
\hline \multirow[t]{2}{*}{ Age of mother, years } & $<21$ & $16(66.7)$ & $8(33.3)$ & 0.018 & $2.93(1.11-7.77)^{*}$ \\
\hline & $\geq 21$ & $28(40.6)$ & $4 \mathrm{I}(59.4)$ & & \\
\hline \multirow[t]{2}{*}{ Education of mother } & $\leq 10$ th standard & $29(49.2)$ & $30(50.8)$ & 0.574 & $1.22(0.52-2.86)$ \\
\hline & $>10$ th standard & $15(44.1)$ & $19(55.9)$ & & \\
\hline \multirow[t]{2}{*}{ Socioeconomic status } & Low & $28(48.3)$ & $30(51.7)$ & 0.529 & I.II (0.48-2.57) \\
\hline & Middle/high & $16(45.7)$ & $19(54.3)$ & & \\
\hline \multirow[t]{2}{*}{ Antenatal visits $(\mathrm{n})$} & $\leq 5$ & $8(80)$ & $2(20)$ & 0.039 & $5.22(1.05-26.70)^{*}$ \\
\hline & $>5$ & $36(43.4)$ & $47(56.6)$ & & \\
\hline \multirow[t]{2}{*}{ Order of pregnancy } & $\geq 2$ & $26(5 \mathrm{I})$ & $25(49)$ & 0.294 & $1.38(0.61-3.15)$ \\
\hline & 1 & $18(42.9)$ & $24(57.1)$ & & \\
\hline IFA tablets consumed during & $<100$ & $12(57.1)$ & $9(42.8)$ & 0.276 & $1.73(0.64-4.34)$ \\
\hline antenatal period (n) & $\geq 100$ & $31(43)$ & $4 \mid(57)$ & & \\
\hline \multirow[t]{2}{*}{ Place of delivery } & Primary health center & $16(57.1)$ & $12(42.9)$ & 0.262 & $1.76(0.77-4.31)$ \\
\hline & Higher center & $28(43.1)$ & $37(56.9)$ & & \\
\hline Perceived blood loss during & Heavy/moderate & $36(52.9)$ & $32(47.1)$ & 0.021 & $3.38(1.10-10.33)^{*}$ \\
\hline delivery & Mild & $5(25)$ & $15(75)$ & & \\
\hline \multirow[t]{2}{*}{ Any morbidity postpartum } & Yes & $4(66.6)$ & $2(33.3)$ & 0.277 & $2.35(0.42-13.5 \mid)$ \\
\hline & No & $40(46)$ & $47(54)$ & & \\
\hline IFA tablets consumed during & $<30$ tablets & $32(58.2)$ & $23(41.8)$ & 0.020 & $3.01(1.26-7.19)^{*}$ \\
\hline postpartum period $(n)$ & $\geq 30$ tablets & $12(31.6)$ & $26(68.4)$ & & \\
\hline Anemia at 36 weeks' & Hemoglobin < II g \% & $19(76)$ & $6(24)$ & 0.001 & $5.45(1.92-15.44)^{*}$ \\
\hline gestation & Hemoglobin $\geq \mathrm{II} \mathrm{g} \%$ & $25(36.8)$ & $43(63.2)$ & & \\
\hline
\end{tabular}

Note: *Significant odds ratio.

Abbreviations: IFA, iron and folic acid; $\mathrm{Cl}$, confidence interval; OR, odds ratio. 
Table 4 Logistic regression model for factors associated with anemia at 6 weeks postpartum

\begin{tabular}{|c|c|c|}
\hline $\begin{array}{l}\text { Risk factors for anemia at } 6 \text { weeks } \\
\text { postpartum }\end{array}$ & $\begin{array}{l}\text { Adjusted } \\
\text { OR }\end{array}$ & $95 \% \mathrm{Cl}$ \\
\hline Age of mother ( $<2$ I years) & 2.45 & $1.28-23.86 *$ \\
\hline $\begin{array}{l}\text { Total number of visits to antenatal } \\
\text { clinic }(\leq 5)\end{array}$ & 1.19 & $0.95-1.48$ \\
\hline $\begin{array}{l}\text { Total IFA tablets consumed during } \\
\text { antenatal period }(<100)\end{array}$ & 3.37 & $0.65-17.49$ \\
\hline $\begin{array}{l}\text { Anemia at } 36 \text { weeks (hemoglobin } \\
<\text { II g \%) }\end{array}$ & 10.47 & $2.37-42.34 *$ \\
\hline $\begin{array}{l}\text { Perceived blood loss during delivery } \\
\text { (heavy/moderate) }\end{array}$ & 12.91 & $2.01-61.25^{*}$ \\
\hline Any morbidity during postpartum period & 4.55 & $0.44-47.06$ \\
\hline $\begin{array}{l}\text { Total IFA tablets consumed during } \\
\text { postpartum period ( }<30 \text { tablets) }\end{array}$ & 3.53 & $1.18-11.37 *$ \\
\hline
\end{tabular}

Note: *Statistically significant $(P<0.05)$.

Abbreviations: IFA, iron and folic acid; $\mathrm{Cl}$, confidence interval; OR, odds ratio.

and from other developing countries. ${ }^{4,6,7,9,10}$ This could be due to the fact that the study was done in an area with good antenatal coverage and maternal services by multiple care providers. The finding that $36 \%$ of the women who were previously not anemic became anemic after delivery is almost double the figure reported by Bodnar et al for low-income women in the USA. ${ }^{13}$ During the postpartum period, the hemodilution effect usually wanes and hemoglobin returns to normal. This period is characterized by increased erythropoiesis and expansion of the red cell mass. A fall or inadequate rise in hemoglobin during the postpartum period might be due to excessive blood loss during and after delivery and/or due to inadequate erythropoiesis taking place postpartum, which could be due to depleted iron stores. These poor iron stores often date back to the prepregnancy state and continue throughout the pregnancy, and tip the precarious balance in the postpartum period.

Antepartum anemia has also been found to be an important risk factor for postpartum anemia in several other studies. ${ }^{21,22}$ The iron deficiency present during the antenatal period continues through the postpartum period also. The Centers for Disease Control and Prevention recommend screening for postpartum anemia in all women who have had anemia during the antenatal period. ${ }^{23}$ All these facts clearly point to the importance of prevention and control of anemia during pregnancy.

Heavy/moderate blood loss as perceived by the mother at the time of delivery was a significant risk factor for postpartum anemia. Previous studies from Uganda and Germany have also identified that heavy blood loss perceived by the mother at delivery was significantly associated with anemia during the postpartum period. ${ }^{21,22}$ Excessive bleeding might undermine the efforts made to build ade- quate iron resources through antenatal iron supplementation. However, it has to be mentioned that assessment of perceived blood loss by the mother at delivery and during the postpartum period in this study had limitations. Blood is mixed with amniotic fluid during delivery, and estimation is difficult even by trained observers. It was noted during data collection for this study that the mothers who reported "mild" bleeding did so confidently, but there was considerable overlap between those who reported moderate and heavy bleeding. Grading of postpartum blood loss was estimated from answers to questions concerning number of changes of pads/clothing, which helped the mothers in reaching a conclusion. However, the practice of changing pads/clothes might be variable among mothers. Although many studies have used maternal perception for estimation of blood loss, this method has not been validated in the local community. ${ }^{21}$

Not taking iron and folic acid regularly in the postpartum period has been identified as a risk factor for postpartum anemia. A woman might reach postpartum period after depleting all her iron stores, and supplementation with iron tablets at that time is necessary for the production of red blood cells. In areas where there is a high prevalence of anemia, the World Health Organization recommends continuing supplementation of iron tablets for 3 months into the postpartum period. ${ }^{24}$ Given the magnitude of the problem, continuation of iron supplementation for 3 months postpartum may be warranted.

Younger maternal age is documented as an independent risk factor for anemia during pregnancy. ${ }^{8}$ Self-care options during pregnancy and after delivery, as well as knowledge regarding healthy practices, might improve with increasing maternal age. Incomplete maternal growth, nutritional deficiencies, lesser utilization of prenatal and postnatal services, and other cultural, psychological, and behavioral factors associated with younger maternal age could have contributed to the development of anemia.

The Centers for Disease Control and Prevention, the Institute of Medicine, and the American Congress of Obstetricians and Gynecologists have guidelines for the control and prevention of postpartum anemia. ${ }^{23,25,26}$ However, there are no clear-cut guidelines to address the problem of postpartum anemia in India. The number of postpartum visits seems inadequate, even in this setting. Health workers should be sensitized regarding the problem of postpartum anemia and should be trained to look for clinical features of anemia during their visits to postpartum mothers. Research has to be focused on appropriate strategies to prevent and control postpartum anemia. 
In this study, the sample size was calculated for estimation of changes in hemoglobin but was not adequate to study the risk factors associated with anemia. This explains the wide CIs of the OR estimates. Serial monitoring of hemoglobin at more frequent and specific intervals for a longer duration in the postpartum period would give a better idea regarding changes in hemoglobin levels during this time. Anemia other than iron deficiency was not addressed in this study, and the picture would have been clearer with estimation of iron stores using serum ferritin or transferrin saturation.

To summarize, anemia during the postpartum period is an important public health issue, and the rise in hemoglobin after delivery was not adequate in our study population. Anemia during the third trimester of pregnancy, heavy bleeding perceived by the mother during delivery, younger maternal age, and no regular iron supplementation during the postpartum period were identified as significant risk factors associated with anemia at 6 weeks postpartum.

\section{Disclosure}

The authors report no conflicts of interest in this work.

\section{References}

1. World Health Organization. Anemia prevention and control. Geneva, Switzerland: World Health Organization; 2011. Available from: http:// www.who.int/medical_devices/initiatives/anaemia_control/en. Accessed February 10, 2014.

2. Government of India. National Family Health Survey-3. Anemia among Women and Children. Mumbai, India: International Institute for Population Sciences; 2005.

3. Institute of Medicine. Nutrition during pregnancy. Part II: Nutrient Supplements. Chapter 14: Iron nutrition during pregnancy. Washington, DC, USA: National Academy Press; 1990. Available from: http://books. nap.edu/openbook. Accessed August 20, 2011.

4. Goodburn EA, Gazi R, Chowdhury M. Beliefs and practices regarding delivery and postpartum maternal morbidity in rural Bangladesh. Stud Fam Plann. 1995;26:22-32.

5. Bodnar LM, Cogswell ME, Scanlon KS. Low income postpartum women are at risk of iron deficiency. J Nutr. 2002;132:2298-3021.

6. Agarwal KN, Agarwal DK, Sharma A, et al. Prevalence of anaemia in pregnant and lactating women in India. Indian J Med Res. 2006;124: 173-184.

7. Somdatta P, Reddaiah VP, Singh B. Prevalence of anaemia in the postpartum period: a study of a North Indian village. Trop Doct. 2009;39: 211-215.

8. Barroso F, Allard S, Kahan BC, et al. Prevalence of maternal anaemia and its predictors: a multi-centre study. Eur J Obstet Gynecol Reprod Biol. 2011;159:99-105.

International Journal of Women's Health

\section{Publish your work in this journal}

The International Journal of Women's Health is an international, peerreviewed open-access journal publishing original research, reports, editorials, reviews and commentaries on all aspects of women's healthcare including gynecology, obstetrics, and breast cancer. The manuscript management system is completely online and includes

Submit your manuscript here: http://www.dovepress.com/international-journal-of-womens-health-journal
9. Trinh LT, Dibley M. Anaemia in pregnant, postpartum and non pregnant women in Lak district, Daklak province of Vietnam. Asia Pac J Clin Nutr. 2007;16:310-315.

10. Milman N. Postpartum anemia: definition, prevalence, causes, and consequences. Ann Hematol. 2011;90:1247-1253.

11. Bodnar LM, Scanlon KS, Freedman DS, Siega-Riz AM, Cogswell ME. High prevalence of postpartum anemia among low-income women in the United States. Am J Obstet Gynecol. 2001;185:438-443.

12. Pehrsson PR, Moser-Veillon PB, Sims LS, Suitor CW, Russek-Cohen E. Postpartum iron status in nonlactating participants and nonparticipants in the special supplemental nutrition program for women, infants, and children. Am J Clin Nutr. 2001;73:86-92.

13. Bodnar LM, Siega-Riz AM, Miller WC, Cogswell ME, McDonald T. Who should be screened for postpartum anemia? An evaluation of current recommendations. Am J Epidemiol. 2002;156:903-912.

14. Beard JL, Hendricks MK, Perez EM, et al. Maternal iron deficiency anemia affects postpartum emotions and cognition. J Nutr. 2005;135: 267-272.

15. Corwin EJ, Murray-Kolb LE, Beard JL. Low hemoglobin level is a risk factor for postpartum depression. J Nutr. 2003;133:4139-4142.

16. Gibbs RS. Clinical risk factors for puerperal infection. Obstet Gynecol. 1980;55:178-184.

17. Henly S, Anderson C, Avery M. Anemia and insufficient milk in first time mothers. Birth. 1995;22:87-92.

18. Joseph A, Joseph KS, Kamaraj K. Use of computers in primary health care. Int J Health Sci. 1991;2:93-101.

19. Kumar N, Shekhar C, Kumar P, Kundu AS. Kuppuswamy's socioeconomic status scale - updating for 2007. Indian J Pediatr. 2007;74:1131-1132.

20. World Health Organization. Nutritional anemia. Report of a WHO Scientific Group. WHO Technical Report Series, No 405. Geneva, Switzerland: World Health Organization; 1968.

21. Sserunjogi L, Scheutz F, Whyte SR. Postnatal anaemia: neglected problems and missed opportunities in Uganda. Health Policy Plan. 2003;18:225-231.

22. Bodnar LM, Cogswell ME, McDonald T. Have we forgotten the significance of postpartum iron deficiency? Am J Obstet Gynecol. 2005;193:36-44.

23. [No authors listed]. Recommendations to prevent and control iron deficiency in the United States. Centers for Disease Control and Prevention. MMWR Recomm Rep. 1998;4:1-29.

24. World Health Organization. Iron and folate supplementation. Department of making pregnancy safer. Geneva, Switzerland: World Health Organization; 2006. Available from: http://www.who.int/ making_pregnancy_safer/publications/Standards1.8N.pdf. Accessed August 21, 2011.

25. The American College of Obstetricians and Gynecologists. Anemia in pregnancy. Obstet Gynecol. 2008;112:201-207.

26. Institute of Medicine. Iron deficiency anemia: recommended guidelines for the prevention, detection, and management among US children and women of childbearing age. Washington, DC, USA: Institute of Medicine; 1993. Available from: http://www.nap.edu/openbook.php record_id.pdf. Accessed August 21, 2011.

a very quick and fair peer-review system, which is all easy to use. Visit http://www.dovepress.com/testimonials.php to read real quotes from published authors. 